18. Калинова Г.С., Никишова Е.А., Петросова Р.А. Биология. Решение заданий повышенного и высокого уровня сложности. Как получить максимальный балл на ЕГЭ. М.: Изд-во «Интеллект-центр», 2016. 128 с.

19. Лаврентьев Г.В., Лаврентьева Н.Б., Неудахина Н.А. Инновационные обучающие технологии в

\title{
ECOLOGICAL PARKS EDUCATIONAL ENVIRONMENT USAGE AT BIOLOGY LESSONS IN SCHOOLS (ON THE EXAMPLE OF N.A. AVRORIN POLAR-ALPINE BOTANICAL GARDEN-INSTITUTE)
} (C) 2019

Mitina Elena Garisonovna, doctor of pedagogical sciences, professor of Natural Sciences Department; research consultant Murmansk Arctic State University (Murmansk, Russian Federation); N.A. Avrorin Polar-Alpine Botanical GardenInstitute of Kola Scientific Centre of Russian Academy of Sciences (Apatity, Murmansk Region, Russian Federation) Ishchenko Anastasia Vladimirovna, junior researcher of Medical and Biological Technologies Laboratory Kola Scientific Center of Russian Academy of Sciences (Apatity, Murmansk Region, Russian Federation)

Abstract. The paper is devoted to the search of alternative ways to update school Biology curriculum. Creation of educational environment at the premises of ecological parks is considered to be an innovative and promising prospective approach that meets contemporary demands and follows central developmental trends of society. Based on the results of practicing Biology teachers' poll, we give an expediency analysis of engaging ecological parks educational opportunities for school lessons. According to available data as well as based on the structure and the content of biological education prescribed for secondary school, the author's program «Kola Land nature» has been developed. The content of our program is an addition to the General program line «Biology for 6-9 classes» created by V.V. Pasetchnik, it matches the themes of a school Biology course: «Biology as a science of vital nature», «Cellular structure of organisms», «Plant kingdom», «Diversity of fauna», «Ecosystems». Effectiveness evaluation of the author's educational program «Kola Land nature» was realized in the ecological park of N.A. Avrorin Polar Alpine Botanical Garden \& Institute. The obtained data confirm that the program usage as an addition to the basic school Biology course improves the level of its mastering by students.

Keywords: secondary school; biological education; school Biology content; Biology learning process; educational forms; learning outcomes; educational environment; environmental approach; botanical garden; ecological park; author's educational programs.

УДК 371

DOI 10.24411/2309-4370-2019-12305

Статья поступила в редакцию 28.02.2019

\section{ГЛОБАЛЬНАЯ ЦЕЛЬ МЕДИАОБРАЗОВАНИЯ В УСЛОВИЯХ ИНФОРМАЦИОННОГО ОБЩЕСТВА}

(C) 2019

Позднякова Оксана Константиновна, доктор педагогических наук, профессор,

член-корреспондент Российской академии образования, профессор кафедры педагогики и психологии

Самарский государственный соииально-педагогический университет (2. Самара, Российская Федераиия)

Крылова Елена Леонидовна, директор

Филиал «Государственная телевизионная и радиовещательная компания "Самара"» Всероссийской государственной телевизионной и радиовещательной компании (2. Самара, Российская Федераиия)

Аннотация. В статье актуализируется проблема медиаобразования в условиях современного российского общества, позволяющего овладевать умениями и навыками эффективной работы с информацией. Обосновывается, что медиаобразование способствует подготовке прежде всего молодого поколения к жизни в современных условиях, к эффективному восприятию информации и ее осмыслению, к осознанию воздействия различных видов информации на психику, а также к овладению современными техническими средствами невербальной коммуникации. Подчеркивается роль медиаобразования в превращении молодежи в креативных создателей собственного контента, развитие их как гармоничной личности - развитие эмоций, интеллекта, формирование мировоззрения, приобщение к нравственным ценностям. Обозначается роль средств массовой информации в формировании медиакультуры и информационной грамотность населения в целом и детей и молодежи в особенности. Обосновывается, что глобальной целью медиаобразования в условиях информационного общества является построение идеологического фундамента общества. Аргументируется, что одной из важных задач, направленных на достижение глобальной цели медиаобразования является формирование патриотизма, как одной из базовых российских ценностей. Обозначается взаимосвязь патриотического воспитания и медиаобразовательного процесса. Приводится содержание мультимедийного патриотического медиаобразовательного проекта (фестиваля) федерального масштаба Первый Всероссийский медиаконкурс «Русский космос», способствующее развитию личности с помощью и на материале средств массовой информации, получению историко-краеведческих знаний и приобщению к величайшим страницам истории родной страны. Делается вывод о важной роли медиаобразования в подготовке детей, подростков, юношей к жизни в новом технологическом укладе, к работе в условиях многополярности виртуального мира и бесконечного потока разнонаправленной информации.

Ключевые слова: медиаобразование; информационное общество; цель; задачи; информация; информационная грамотность; медиакультура; медиапространство; средства массовой информации; глобальная сеть; медиасреда; медиапродукт; патриотизм; патриотическое воспитание; коммуникативная стратегия. 
Цифровая экономика - один из приоритетных национальных проектов страны, к реализации которого активно подключились предприятия и организации Самарской области, крупнейшего региона России, где создается практическая база для развития технологий будущего. Сегодня медиатехнологии являются неотъемлемой ее частью.

Молодежь как носитель нового типа мышления не только с легкостью овладевает новациями в мире digital, но и эффективно использует его доступные средства. Это формация с вирусной самоорганизацией, где вовлечение в процесс общественности становится одной общей целью и способно к мобилизации в короткие сроки. Именно осознание не только возможностей, но и угроз, таящихся в медиапространстве, повлекло за собой дискуссию о необходимости экологичного отношения к медиасреде и выработке правил системного взаимодействия, формирования навыков получения и потребления информации, информационной грамотности, а значит и медиакультуры в целом.

В соответствии с Концепцией долгосрочного социально-экономического развития Российской Федерации на период до 2020 года медиаобразование входит в список долгосрочного социально-экономического развития страны [1]. Основные усилия государства направлены на создание информационного общества, развитие коммуникативных технологий, что способствует повышению качества жизни, улучшению социального самочувствия, а также политической, экономической, культурных сфер жизни людей. Целью государственной политики становятся образование, здравоохранение и соцзащита, повышение качества подготовки специалистов этих отраслей, а также содействие развитию культуры и СМИ на основе информационно-коммуникационных технологий в том числе «расширение использования информационных и телекоммуникационных технологий для развития новых форм и методов обучения, в том числе дистанционного образования и медиаобразования» [1].

Современный человек, проживающий в условиях информационного общества, ежесекундно сталкивается с огромным количеством информации, в мире которой ему необходимо ориентироваться. Для того, чтобы эффективно это осуществить человеку необходимо обладать соответствующими умениями и навыками и прежде всего умениями, позволяющими отделять достоверную информацию от недостоверной. Как пишет Е.В. Якушина, здесь важно «владение навыками грамотного поиска информации, правильно задавать корректный поиск, адекватно формулировать запрос; анализировать источники информации; критически отбирать и оценивать достоверность информации; проверять фактические ошибки; изучать синтаксический план функционирования информации, логику ее построения, структуру; отличать аргументацию научную от ненаучной, корректную от некорректной; сравнивать смысл, заложенный в информационном сообщении, со своими базовыми званиями по той или иной проблеме, в случае их нехватки обращаться к дополнительной литератуpe, к другим источникам информации; систематизировать информацию, искать срытый смысл» [2].

С нашей точки зрения, особенно важно, чтобы навыками работы с информацией научились дети и подростки, так как именно на них недостоверная ин- формация оказывает негативное влияние в силу их возрастных и психологических особенностей. К тому же современный мир динамично развивается, расширяя границы своего проникновения и влияния на формирование личности. Процесс глобализации затрагивает и медиасферу, и многие другие отрасли, конвергирует ресурсы распространения и инициирует междисциплинарный обмен. Все это порождает дискуссию о необходимости формулирования цели и задач эффективного медийного образования, определения его функций и инструментария.

Несмотря на то, что глобальная сеть как важнейший источник медиасреды появилась сравнительно недавно, термин «медиаобразование» существует с середины прошлого века. Вклад в развитие данного термина был внесен как зарубежными D. Adams и M. Hamm, [3], G. Branston и R. Stafford [4], D. Buckingham [5], L.L. Johnson [6], S. Krucsay [7], N. Stevenson [8] и др., так и российскими А.В. Шариков [9], А.В. Федоров [10-12], Л.С. Зазнобина [13], Е.В. Мурюкина [14], Н.П. Рыжих [15], И.В. Челышева [16] и др. учеными.

Классическая теория медиаобразования, по утверждению А.В. Федорова, включает три основных направления. Первое направление связано с профессиональным образованием, в процессе которого осуществляется подготовка специалистов в сфере медиа (журналисты, продюсеры, режиссеры, операторы и т.д.) Второе - это подготовка будущих педагогов для различных типов образовательных учреждений. И, наконец, третье направление - это медиаобразование «как предмет или дисциплина в школах и иных учебных заведениях, которое может быть как самостоятельным, так и интегрированным в традиционные дисциплины» [11, с. 42].

Отечественные педагогические словари и энциклопедии трактуют понятие «медиаобразование» как «направление в педагогике, выступающее за изучение школьниками закономерностей массовой коммуникации (прессы, телевидения, радио, кино, видео и т.д.)» $[17$, с. 555]; «направление в образовании, ориентированное на изучении соответствующих информационных технологий с целью подготовки учащихся к жизни в современном информационном обществе, а также формирование медиаграмотности, способности и готовности применять новые технические средства в практической деятельности» $[18$, с. 27].

Основная задача медиаобразования видится в подготовке учащихся к жизни в современных условиях, к эффективному восприятию информации и ее осмыслению, к осознанию воздействия различных видов информации на психику, а также к овладению современными техническими средствами невербальной коммуникации.

Однако во многих работах российских ученых в области медиаобразования данный термин понимается более широко. Научный диалог ученых и исследователей относительно пересмотра классических определений в системе медиаобразования обусловлен не только процессом модификации устоявшихся концепций, но и стремительным развитием технологий, появлением новых социальных медиа (блоги, посты, YouTube-каналы и т.д.). Сегодня все больше внимания уделяется медиаобразованию с точки зрения развития личности, индивидуума. Так, один из основоположников российского медиаобразования А.В. Федоров утверждает, что «медиаобразование - 
это не просто направление в педагогике, а процесс развития личности с помощью и на материале средств массовой коммуникации (медиа), который формирует культуру общения с медиа, развивает творческие и коммуникативные способности, критическое мышление, обучает различным формам самовыражения при помощи медиатехники» [11, с. 39]. А.В. Шариков, так же внесший значительный вклад в развитии теории и практики отечественного медиаобразования, под термином медиаобразование понимает «процесс передачи и усвоения знаний, умений и навыков, связанных с массовой коммуникацией» $[9$, с. 5]. Собственно в педагогической литературе термина «медиаобразования» рассматривается, например, как «процесс образования, развития, формирования личности на материале и через средства массовой коммуникации» (Т.А. Стефановская $[19$, c. 225]).

Итак, можно смело утверждать, что целью медиаобразования является не только обучение и овладение медиатехнологиями, но и превращение пользователей в креативных создателей собственного контента, развитие их как гармоничной личности развитие эмоций, интеллекта, формирование мировоззрения, приобщение к нравственным ценностям. Система медиаобразования играет колоссальную роль в воспитании личности, развитии индивидуальности, аналитических способностей, умению работать в медиапространстве и управлять большими проектами. Медиасреда - это сфера, где мультимедийность, интерактивность, коммуникации должны работать на всеобщее благо, и образование играет здесь далеко не последнюю роль.

Как уже отмечалось, медиаобразование является приоритетным направлением государственной политики России. Необходимо формировать медиакультуру и информационную грамотность населения в целом и детей и молодежи в особенности. Значительную роль в этом процессе должны сыграть СМИ. Сегодня информационное пространство безгранично как Вселенная, количество средств массовой коммуникации неуклонно растет, отсутствие лицензирования в интернете позволяет зачастую неподготовленным автором объявлять себя средством массовой информации. Стали распространенными такие явлениям, как агрегатор новостей - фактический дубль информагентств, небольшие редакции, перепечатывающие пресс-релизы и не несущие ответственности за содержание. Стало также модным явление под названием «фейк ньюс» (фейковая новость), заведомо содержащая ложь и провокацию.

Все вместе позволяет говорить о насущной потребности формировать не только культуру медиасреды, но и культуру социального субъекта в массовом коммуницировании и потреблении. Можно смело утверждать, что СМИ также формируют медиакультуру аудитории через реализацию базовых функций - просветительской, педагогической, воспитательной, пропагандистской и др. По сути, журналистика является инструментом медиаобразования, поскольку несет в жизнь культуру речи, яркость образов, примеры и образцы для подражания. СМИ фактически строят идеологический фундамент общества, что и является глобальной целью медиаобразования в условиях информационного общества. Для достижения данной цели необходимо решить ряд задач, одной из которых является формирование пат- риотизма, как одной из базовых российских ценностей.

Считается, что медиаобразование в России начиналось с патриотического кино и детской прессы. Тогда это явление называлось кинопедагогикой и было пропитано идеалами шестидесятых, «первой оттепелью» и духом свободы. Так Г.А. Поличко, к примеру, считает, что «отечественный экран переживал невиданный ренессанс, позволивший вполне справедливо считать кино не только мощным средством эстетического развития личности, но и фактором формирования национальной гордости, духовности, внутреннего мира личности» $[20$, с. 6]. Г.А. Поличко также описывает медиаинструменты, а именно проведение медиаобразовательных фестивалей, «с помощью которых возможно приобщение детей и молодежи к отечественной и мировой киноклассике, формирование и развитие у них экранного языка, художественного вкуса, критического отношения к агрессии электронных СМИ, а также восстановление культурных связей на бывшем постсоветском пространстве» [21, с. 46].

Многие исследователи сходятся во мнении, что духовно-патриотическое воспитание тесно связано с медиаобразовательными процессами. Развитие художественных способностей, приобщение к нравственным ценностям невозможно без опоры на чувство любви к малой Родине, на знание истории родного края, на базисные ценности родной земли.

Так, Ю.Н. Усов обращает внимание на необходимость развития у обучающихся «навыков художественно-творческой деятельности в области кино, телевидения, видео и использовать их в процессе освоения духовного пространства своего региона, края, республики с помощью экранных искусств на специальных учебных занятиях и во внеклассной работе» [22, с. 29].

Для Г.Ю. Франко целью занятий по экранной культуре является воспитание потребности «в выстраивании и упорядочивании иерархии смыслов духовного, культурного мира и предлагает проводить такие занятия в контексте нравственного «самостроительства» личности, основывающегося на высоких идеалах отечественной культуры» [23, с. 166-167].

В анкетировании, проведенном в 2008 году среди известных медийных личностей [24], одним из вопросов был вопрос, касающийся ценностей, которые они стремятся реализовать в своем творчестве. Значительная часть опрошенных, среди которых были Ф.С. Хитрук, А.Б. Джигарханян, Н.В. Мордюкова и другие известные деятели киноискусства, назвала такие ценности как «любовь к родине», «духовность», «справедливость». Тем самым, можно говорить о том, что киноискусство и медиакультура в целом обладают большими возможностями в формировании нравственности, в воспитании патриотизма зрительской аудитории. Использовать такие возможности просто необходимо в медиаобразовательной деятельности.

Практический пример патриотического воспитания медиа средствами приводится в работе Н.П. Рыжих «Использование медиаобразования в воспитании детей» [25]. По мнению автора, воспитание патриотизма обучающихся возможно не только на классных часах соответствующей тематики, но и на занятиях медиаклуба, что позволяет использовать как документальные, так и художественные фильмы, теле- 
передачи, посвященные истории Отечества, выдающимся соотечественникам и т.д. Например, о Великой Отечественной войне, о географических открытиях, о героях войны и труда, об освоении космоса и т.д. Н.П. Рыжих в качестве эффективных форм и средств патриотического воспитания в процессе работы медиаклуба называет лекционные занятия патриотической тематики, письменные работы (рецензии), викторины, конкурсы с использованием киноматериалов, дискуссии. Так в качестве общей цели дискуссий выступает создание ситуации нравственного общения по результатам просмотра телепередачи или фильма. Задачами дискуссий выступают формирование у обучающихся умений и навыков осмысленного анализа просмотренного видеоматериала, понимания его эмоционального воздействия на аудиторию, развитие способности оценивать действия и поступки героев фильмов и телепередач. Как отмечает Н.П. Рыжих: «Выбор форм патриотического воспитания на медиаматериале может быть самым разнообразным в зависимости от возраста учащихся, их индивидуальных особенностей, интересов, вида образовательного учреждения: создание школьниками собственных медиатекстов (видеофильмов, фотофильмов, слайдов, газет, Интернет-страничек и пр.) в процессе туристско-краеведческой и экскурсионной деятельности (история и культура родного края, ратные подвиги и судьбы соотечественников, семейные родословные и народное творчество) в школьных кружках, на станциях юных туристов, в туристических центрах, базах. Это также подготовка школьниками репортажей, отчетов о походах, тематических экскурсиях с использованием медиа технологий; использование учащимися совместно с педагогами мультимедиа при создании самодеятельных краеведческих, военно-патриотических, этнографических школьных музеев» [25].

Ярким примером мультимедийного патриотического медиаобразовательного проекта (фестиваля) федерального масштаба стал проведенный в 2016 году Первый Всероссийский медиаконкурс «Русский космос». Это был классический пример процесса развития личности с помощью и на материале средств массовой информации, получения историкокраеведческих знаний и приобщения к величайшим страницам истории родной страны.

2016 год знаменателен особенной для нашей страны датой - 55-летием со дня первого полета человека в космос. Интерес к событиям 12 апреля 1961 года, к личности первого космонавта планеты, к истории освоения космического пространства не только не ослабевает, но и объединяет людей. Каждый ребенок помнит обаятельную улыбку первого космонавта. Одно лишь упоминание даты «12 апреля 1961» года заставляет каждого человека испытывать чувство великой гордости за свою страну, а любого самарца - за свой город. Вклад куйбышевцев в покорение космоса сложно недооценить, и сегодня наши земляки ежедневно трудятся на благо авиации и космонавтики.

Главными целями I Всероссийского медиа конкурса «Русский космос» было позиционирование региона как столицы космической отрасли; стимулирование региональные и федеральные СМИ к созданию и распространению материалов об истории ее развития и становления; широкое вовлечение гражданского общества в процесс создания медиапродукта и осмыслению исторического пути России. Можно утверждать, что сверхзадачей проекта было патриотическое воспитание граждан медиаобразовательными инструментами. Для достижения целей были поставлены следующие основные задачи:

- организация и проведение творческого конкурса;

- установление творческих контактов между журналистами страны;

- сохранение и популяризация истории развития российской космонавтики;

- формирование единого коммуникативного пространства.

Была выработана глобальная коммуникативная стратегия, включавшая информационное сопровождение на федеральных и региональных каналах, в интернет-пространстве и соцсетях, поскольку в том периоде именно успешная космическая отрасль могла стать объединяющей темой, способной стать национальной идеей, объединяющей поколения, профессии, регионы, и т.д. Главной составляющей коммуникативной стратегии проекта являлась организация обратной связи с аудиторией, вовлечение ее в эфирные теле- и радио-форматы, мотивация к созданию творческих проектов и ярких идей, посвященных космосу.

Всероссийский медиа конкурс «Русский космос» был реализован в два параллельных этапа: федеральный и региональный. Федеральный этап реализации проекта был рассчитан исключительно на профессиональные работы и включал в себя 5 номинаций: «Лучший репортаж», «Лучшая просветительская программа или цикл», «Лучший документальный фильм», «Лучший спецпроект», «Лучшая радиопрограмма или цикл».

Конкурс привлек максимальное количество участников со всей России: теле- и радиожурналистов, авторов, документалистов более чем из 40 регионов РФ.

Региональный этап конкурса был придуман для жителей Самарской области, которые через свои конкурсные работы рассказывали о грандиозном вкладе самарцев в космическую отрасль. Работы принимались по следующим номинациям: «Лучший детский рисунок», «Лучшая компьютерная графика», «Лучший спецпроект», «Космос в моей жизни», «Лучшая фоторабота».

В перечне номинаций можно четко проследить медиа составляющую проекта как инструмента образовательных и просветительских процессов, воспитание патриотического сознания и создания глобального космического архива Самарского региона.

Старт проекта «Русский космос» был дан в декабре 2015 года, с момента подачи первых работ на региональный этап. Прием заявок продлился до 12 апреля 2016 года, за это время более 1500 работ было прислано жителями Самарской области. Лучшие из лучших определялись в ходе интерактивного народного голосования на сайте ГТРК «Самара» и в специально созданной группе социальной сети «VK», что можно по праву считать успешным примером продвижения мультимедийной грамотности, мотивацией для пользователей обучиться навыкам коммуникации в медиа пространстве.

Номинации конкурса «Русский космос» стали не только мультиформатной выставкой достижения отечественной космонавтики. Они дали возможность жителям Самарской области рассказать всему регио- 
ну об уникальных фото архивах, отражающих историю целого поколения, показать через объектив фотокамеры и видео культовые места родного города, связанные с космической историей, мотивировать участников на освоение медиа знаниями и сформировать патриотическое сознание у представителей молодого поколения. В ходе работы над проектом были использованы следующие приемы и средства продвижения:

- масштабное анонсирование мероприятий проекта на трех телеканалах и трех радиостанциях;

- создание и трансляция тематических рубрик, информационных сюжетов, промо-роликов, специальных репортажей, программ, спик-шоу на теле- и радиоканалах;

- прямая коммуникация и обмен информацией с профессиональными журналистскими объединениями со всей России и жителями Самарской области;

- организация мероприятий с приглашением непосредственных участников всех этапов проекта (российскими космонавтами, ветеранами космической отрасли, жителями Самарской области);

- работа с другими электронными, печатными СМИ, интернет-порталами и региональными коллегами для максимально полного освещения этапов, масштабности и вовлеченности участников в конкурс;

- поддержка проекта через интернет-сайт tvsamara.ru и страницы ГТРК «Самара» в социальных сетях (facebook.com, vk.com, ok.ru, twitter.com, youtube.com).

Контентное насыщение перечисленных выше средств стало результатом большой организационной и исследовательской работы, проведенной журналистами ГТРК «Самара», были изучены и осмыслены собрания сочинений и научных трудов разных авторов, выявлены яркие примеры служения Отечеству и описаны героические биографии космонавтов. Нужно сказать, что федеральный этап медиаконкурса «Русский космос» отразил огромный интерес к космической теме в профессиональном сообществе журналистов из регионов где, как может показаться на первый взгляд, связь с космосом очень условная. Представители СМИ от Владивостока до Калининграда прислали более 180 работ различных форматов: репортажи, просветительские программы, документальные фильмы, спецпроекты и радиопрограммы.

Кульминацией Всероссийского медиа конкурса «Русский космос» стала церемония награждения победителей. Зрители церемонии закрытия увидели яркое космическое шоу с эффектными акробатическими номерами и 3D эффектами - ту самую мультимедийную реальность, которая появилась у человечества благодаря освоению космоса. Федеральный и региональный этапы медиаконкурса «Русский космос» объединили крупнейшие регионы страны. Тысячи зрителей ГТРК «Самара» поддержали проект. И, что особенно важно - дети.

Космос - это предмет нашей национальной гордости. Не в каждом регионе найдется такая значимая, объединяющая всех тема, в которую вплелись события более чем полувековой истории страны. Сегодня, «Самара - космическая столица» - это не просто бренд, а страница истории Самарской области, напоминающая об успехах покорения звезд и перспективах развития космической отрасли с участием крупнейших самарских предприятий.

Проект был реализован силами ГТРК «Самара» при поддержке Полномочного представителя Прези- дента РФ в ПФО, Госкорпорации «Роскосмос»/РКЦ «Прогресс», Правительства Самарской области, Всероссийская государственная телевизионная и радиовещательная компания (ВГТРК)/ГТРК «Самара», «Самарской областной организацией Союза журналистов России». Интерес к конкурсу и желание его поддержать на высоком политическом и промышленном уровне был предопределен высокой социальной миссией проекта - поиск национальной идеи, патриотическое воспитание граждан через реализацию функций СМИ и освоению средств массовых коммуникаций. Подтверждением, что цель была достигнута, могут служить следующие факты:

- более 80 регионов России стали участниками конкурса;

- более 3 млн жителей Самарской области стали аудиторией трех ведущих телевизионных каналов, трех радиостанций, восьми социальных сетей и интернет-пространства;

- было размещено более 1 тыс. анонсирующих роликов, около 500 сюжетов, более 100 эксклюзивных тематических миниформ в телевизионном и радио эфире, 20 радио и телевизионных программ;

- более 200 гостей собрались со всей России;

- 2000 зрителей присутствовало на церемонии закрытия конкурса;

- более 100 писем, присланных в адрес редакции от жителей Самарской области с историями, эксклюзивными архивными документами и фотографиями, связанными с космической отраслью;

- более 300 телефонных звонков от жителей Самарской области в адрес редакции;

- более 200 комментариев и сообщения о проекте на сайте компании и в социальных сетях;

- более 20 партнерских СМИ;

- около 200000 «лайков» за участников конкурса в соцсетях.

Подводя итог, можно сказать, что медиаобразовательная цель проекта была достигнута. Большое число работ, представленных на конкурсе, были посвящены популяризации достижений отечественной науки и промышленности, вкладу Самарских ученых, конструкторов, огромных коллективов предприятий космической отрасли родного края. У молодежи, на которую в первую очередь были ориентированы все замыслы, сформировались глубокие знания о космической отрасли, приверженность идеалам родной земли, чувство сопричастности героической романтике покорителей космоса. У представителей старшей аудитории, которых проект вовлек в пространство интернета, заставил интерактивно голосовать и коммуницировать, появились навыки работы с компьютером и желание дальше завоевывать это пространство.

Очевидно, что медиаобразование, которое изучает закономерности массовой коммуникации, способно готовить новое поколение к жизни в новом технологическом укладе, учить работе в условиях многополярности виртуального мира и бесконечного потока разнонаправленной информации в интернете. Навыки, которые прививаются в процессе медиаобразования, помогают человеку грамотно дифференцировать факты, осознавать последствия их влияния и воздействия на психоэмоциональную составляющую, а также овладевать техническими возможностями с целью общения на основе различных форм коммуникации. И в этом, безусловно, видится прогресс и закон эволюции человечества. 


\section{Список литературы:}

1. О Концепции долгосрочного социально-экономического развития Российской Федерации на период до 2020 года: распоряжение Правительства РФ от 17.11.2008 № 1662-р [Электронный ресурс] // http://consultant.ru/document/cons_doc_LAW_82134/e2 6832f0246ec65942dfa2b4fbb2ddf208194056.

2. Якушина Е.В. Медиаобразование. Как проверить достоверность информации в Интернете? [Электронный ресурс] // Медиа. Информация. Коммуникация. Электронный журнал. 2013. № 6. http://mic.org.ru/index.php/new/215-medi.

3. Adams D., Hamm M. Literacy in a Multimedia Age. Norwood, Massachusetts: Christopher-Gordon Publishers, 2001. 199 p.

4. Branston G., Stafford R. The Media Student's Book. London and New York: Routledge, 1999. 468 p.

5. Watching Media Learning. Making Sense of Media Education / ed. D. Buckingham. London; New York; Philadelphia: The Falmer Press, 1990. 234 p.

6. Johnson L.L. Media Education and Change. New York; Washington: Peter Lang Publishing, 2001. 182 p.

7. Educating for the Media and the Digital Age / ed. S. Krucsay. Vienna: Austrian Federal Ministry of Education and UNESCO, 1999, $276 \mathrm{p}$.

8. Stevenson N. Understanding Media Cultures. Social Theory and Mass Communication. London; Thousand Oaks; New Delhi: Sage Publications, 2002. 255 p.

9. Шариков А.В. Медиаобразование: мировой и отечественный опыт. М.: Изд-во Академии педагогических наук СССР, $1990.66 \mathrm{c}$.

10. Федоров А.В. Медиаобразование сегодня: содержание и менеджмента. М.: Изд-во Гос. ун-та управления, 2002. $80 \mathrm{c}$.

11. Федоров А.В. Медиаобразование: История, теория и методика. Ростов-на-Дону: Изд-во ЦВВР, $2001.708 \mathrm{c}$.

12. Федоров А.В. Развитие медиа компетентности и критического мышления студентов педагогического вуза. М.: Изд-во МОО ВПП ЮНЕСКО «Информация для всех», 2007. 616 с.
13. Зазнобина Л.С. Медиаобразование, интегрированное с базовым: Опыт организации экспериментально-исследовательской работы коллектива школы 858 ЮО г. Москвы. М.: Изд-во Южного округа управления московского образования. 1999. 173 с.

14. Мурюкина Е.В. Диалогическая концепция культуры как методологическая основа медиаобразования // Медиаобразование. 2005. № 3. С. 42-55.

15. Рыжих Н.П. Медиаобразование в свете диалога культур // Вестник Таганрогского государственного педагогического института. 2006. № 2. С. 136-139.

16. Челышева И.В. Зарождение и начало развития медиаобразования в России (1900-1934) // Медиаобразование. 2005. № 1. С. 7-25.

17. Российская педагогическая энциклопедия. В 2 т. Т. 1 / гл. ред. В.В. Давыдов. М.: Большая российская энциклопедия, 1993. $608 \mathrm{c}$.

18. Полонский В.М. Большой тематический словарь по образованию и педагогике. М.: Народное образование, 2017. $840 \mathrm{c}$.

19. Стефановская Т.А. Педагогика: наука и искусство. М.: Совершенство, 1998. 368 с.

20. Поличко Г.А. Киноязык, объясненный студенту. М.; Рязань: Русское слово, 2006. 201 с.

21. Основы кинофестивального менеджмента / под ред. члена союза кинематографистов РФ Г.А. Поличко. М., 2003. 209 c.

22. Усов Ю.Н. Программа учебного курса «Основы экранной культуры» для 9-11 классов общеобразовательной школы // Основы экранной культуры. Цикл программ / рук. Ю.Н. Усов. М.: РАО, 1998. С. 29-45.

23. Франко Г.Ю. Искусство кино и отечественная культура // Программы дополнительного художественного образования детей. М.: Просвещение, 2005. C. $166-181$.

24. Мурюкина Е.В. Кинематографическое сообщество: цели киноискусства и кинообразования в России // Медиаобразование. 2009. № 1. С. 67-85.

25. Рыжих Н.П. Использование медиаобразования в воспитании детей. Таганрог: Изд-во Таганрог. гос. пед. ин-та, 2011. 232 с.

\section{THE GLOBAL GOAL OF MEDIA EDUCATION IN THE INFORMATION SOCIETY}

(C) 2019

Pozdnyakova Oksana Konstantinovna, doctor of pedagogical sciences, professor,

corresponding member of Russian Academy of Education, professor of Pedagogy and Psychology Department Samara State University of Social Sciences and Education (Samara, Russian Federation)

Krylova Elena Leonidovna, director

Branch «The Russian Television and Radio Broadcasting Company "Samara"» of The Russian Television and Radio Broadcasting Company (Samara, Russian Federation)

Abstract. The following paper actualizes the problem of media education in the conditions of modern Russian society, allowing to master the skills and abilities to work effectively with information. It is substantiated that media education contributes to training the younger generation, first of all, for life in modern conditions, for effective perception of information and its comprehension, for understanding the impact of various types of information on the psyche, as well as for mastering modern technical means of nonverbal communication. The role of media education in the transformation of young people into creators of their own content, their development as harmonious individuals - development of emotions, intelligence, development of worldview, familiarization with moral values. The role of mass media in the development of media culture and information literacy of the population in general and of children and young people in particular is indicated. It is substantiated that the global goal of media education in the conditions of the information society is to build an ideological foundation of society. It is argued that one of the important tasks aimed at achieving the global goal of media education is the formation of patriotism, as one of the basic Russian values. The relationship between patriotic education and the media education process is indicated. The content of the multimedia patriotic media education project (festival) of the federal scale, the First All-Russian Media Competition «Russian Cosmos», promotes development of the individual through media, acquires historical 
knowledge of local lore and familiarizes with the greatest pages of the history of his/her native country. The conclusion is made about the important role of media education for training children, adolescents and young people to live in a new technological structure, to work in conditions of the multipolarity of the virtual world and an endless stream of multidirectional information.

Keywords: media education; information society; goal; objectives; information; information literacy; media culture; media space; media; global network; media environment; media product; patriotism; patriotic education; communication strategy.

УДК 378: 177.1

DOI $10.24411 / 2309-4370-2019-12306$

Статья поступила в редакцию 14.02.2019

\section{ФОРМИРОВАНИЕ КУЛЬТУРЫ ПОВЕДЕНИЯ СТУДЕНТОВ ВУЗА СРЕДСТВАМИ ТЕХНОЛОГИЙ ЛИЧНОСТНО ОРИЕНТИРОВАННОГО ОБРАЗОВАНИЯ} (C) 2019

Цепкова Анжелика Николаевна, кандидат педагогических наук, преподаватель кафедры высшей математики и экономико-математических методов Самарский государственный экономический университет (2. Самара, Российская Федераиия)

Аннотаиия. В статье обосновывается, что одним из способов решения задачи формирования культуры поведения студентов вуза является реализация преподавателем технологий личностно ориентированного образования. Обозначается специфика поступков-слов и поступков-дел в поведении человека. Раскрывается различие между действием-операцией (рассматривается безотносительно его морального, нравственного значения) и действием-поступком (рассматривается с точки зрения морального, нравственного значения). Обосновывается эффективность технологий личностно ориентированного образования для формирования культуры поведения студентов через обращение к основным положениям парадигмы личностно ориентированного образования: положение о ценностях личностно ориентированного образования (личность, культура, творчество), положение о цели личностно ориентированного образования (воспитание целостного человека культуры, природная, социальная и культурная сущности которого находятся во взаимосвязи); положение о функциях личностно ориентированного образования (гуманитарная, культуросозидательная, интегрирующая). Показывается специфика личностно ориентированного образования, заключающаяся в том, что, вопервых, жизненные ситуации, воссоздаваемые в образовательном пространстве личности, требуют организации личностного способа жизнедеятельности воспитуемого; во-вторых, особое место занимает развитие ценностно-смысловой сферы сознания воспитанников, в то время как в рамках традиционной образовательной парадигмы акцент делается на развитии познавательной сферы. Рассматривается триада «задача - диалог игра» как база технологий личностно ориентированного образования. Приводятся примеры игр, построенных с использованием технологий личностно ориентированного образования и способствующих формированию культуры поведения студентов (игра «Вербальное поведение (уверенное, неуверенное и грубое)»; игра «Невербальные формы уверенного, неуверенного, грубого поведения»; игра «Чувство собственного достоинства»; игра-дискуссия «Умейте чувствовать рядом с собой человека»; игра-метафора, игра-самокритика, игра - выбор тактики).

Ключевые слова: студент; культура; поведение; технология; образование; воспитание; личностно ориентированное образование; средство; формирование; вуз; действие-поступок; действие-операция; функции; диалог; игра; игра-метафора; игра-самокритика; игра - выбор тактики.

Утрата обществом своих гуманистических функций начинается тогда, когда образование перестает отвечать на вопрос: «Как жить достойно?» Именно поэтому одной из важнейших задач, стоящих сегодня перед педагогикой, становится возрождение смыслообразующей роли образования в жизни и конкретного человека в отдельности, и в целом общества. Современное образование должно удовлетворять интересы личности, общества и государства. Если личность заинтересована в свободном саморазвитии, в становлении индивидуальности, то общество заинтересовано в том, чтобы в основаниях саморазвития личности находились нравственные ценности, а образование создавало условия для формирования личности нравственной, обладающей внутренней культурой.

Среди многих проблем, характерных для современного этапа развития российского общества, особо выделяется проблема культуры поведения молодых людей. Средства массовой информации, к сожале- нию, часто представляют негативные примеры поведения, которые дети, подростки, юноши, воспринимают как норму. Тем самым формирование культуры поведения молодежи становится одной из актуальных задач, стоящих перед образованием.

Поведение человека состоит из поступков-слов и поступков-дел. Поступки-слова направлены на конкретного адресата и определяют вербальное поведение человека. Поступок-слово считается совершенным в том случае, когда присутствует «некоторый субъективный всплеск на стороне адресата, который принимает и декодирует адресуемую ему информацию в рамках совершаемого поступка» (В.А. Василенко [1, с. 103]). В отличие от поступка-слова, поступок-дело не всегда завершается реакцией адресата. Как утверждает С.Ф. Анисимов, любой поступок обладает ценностным значением и потому возбуждает к себе «то или иное, положительное или отрицательное отношение, реакцию одобрения или осуждения» $[2$, с. 370$]$. 